\title{
Über Salben - oder den Eigenwert der Darreichungsform des Medikaments
}

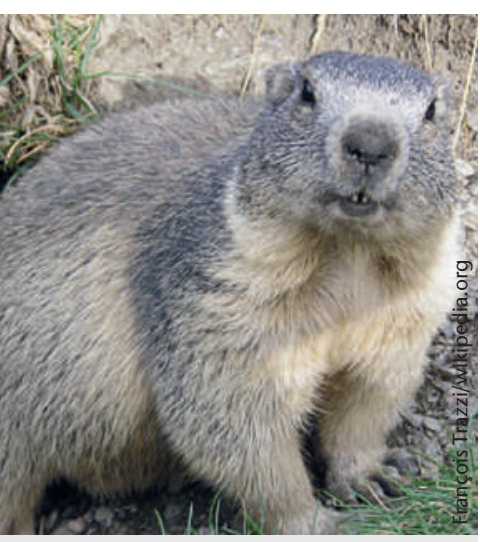

Murmeltier, noch nicht zu Salbe verarbeitet.
Wie schaffen es Hexen zu fliegen? Mit dem Besen, natürlich! Aber nicht nur. Die Kulturgeschichte des Irrationalen kennt die Flugsalbe, mit der sich die angeblichen Hexen vor dem Take-Off in ihren verdienten Hexensabbat ihre Geschlechtsteile tüchtig eingerieben haben sollen.

Es ist kein Zufall, dass der Treibstoff für die damaligen (wohl eher halluzinogenen) Rundflüge wenn überhaupt, dann über den Weg der Einreibung mit einer Salbe verabreicht wurde. Die Salbe war neben dem Arzneipflaster eine beliebte Darreichungsform von Medikamenten in der Vormoderne.

Ganz anders war dies etwa in den pillenfreudigen 1960er Jahren: In einer US-Fernsehserie konnte die Hauptfigur, der klassische Angsthase Stanley Beamish, plötzlich «wie ein Adler fliegen und jeden Bösewicht besiegen. Denn seine grosse Stunde kam immer, wenn er Pillen nahm!» So das Intro und der deutsche Serientitel. Das prüde US-Fernsehen hätte es damals auch weniger goutiert, wenn sich Stanley Beamish vor der Schurkenjagd wie die Hexen mit Superheldensalbe eingerieben hätte.

Als ich vor vielen Jahren einmal mithalf, ein Sommerlager mit Kindern von weither zu betreuen, hat die Lagerleiterin den heimwehkranken Kleinen die Brust mit «Heimwehsalbe» eingerieben. Das hat bestens funktioniert - ich kann es für den Notfall nur weiterempfehlen. Die Salbe sollte einfach angenehm in Konsistenz und Geruch sein.

Streng medizinisch gesehen macht die Anwendung von Salben Sinn, wenn die Substanz lokal über die Haut oder auf der Haut wirken soll. Oder, wie bei den Patches, weil die transdermale systemische Wirkstoffabgabe verträglicher und kontrollierbarer sein kann als mit anderen Darreichungsformen und über andere Verabreichungswege.

Bei der «Heimwehsalbe» liegt der Sinn woanders. Da ist es neben allem möglichen Placebo auch die beruhigende Sinnlichkeit des Applizierens. Allein schon der Akt des Einreibens mit der warmen, anschmiegsamen Hand. Das ist eine noch viel persönlichere Verabreichung als ein in den Mund geschobener Löffel mit sorgsam abgezählten Arzneitropfen. Es ist der direkte Hautkontakt, das langsame Einziehen, vielleicht der Duft. Wenn ich eine Frau wäre, würde ich jetzt wahrscheinlich anfügen: genau wie beim Schminken!

Schmieren und Salben hilft auch heute allenthalben, allein schon durch die Konsistenz - genauer: die Taktilität der Salbe. Welcher Nutella-Liebhaber würde dies bestreiten wollen? Wäre die Schweizer Konditorenkunst denkbar ohne die extremen Taktilitätskontraste der (ganz frischen) Cremeschnitte im Mund? Für dieses sinnliche Feuerwerk nimmt man auch verzweifelte Durchschneide-Versuche in Kauf. Und welcher erfolgreiche Autodesigner dürfte den ästhetischen Marketing-Mehrwert des Sich Anfühlens ignorieren? Das gleiche gilt auch für Arzneisalben.

Manchen Salben wohnt zusätzlich zum allfälligen therapeutischen Nutzen eine eigene Aura des Besonderen inne: der Wund- und Heilsalbe, der dunklen Zugsalbe, der «Weissen Salbe» ohne Wirkstoff. Früher vielleicht der «grauen» Quecksilbersalbe gegen Syphilis oder der magischen «Waffensalbe», die Ingredienzien aus Leichenteilen enthielt und schwere Wunden heilen sollte. Da wundert es kaum, wenn auf dem Internetmarkt eine sonderbare «Schwarze Salbe» kursiert, die angeblich Krebs diagnostizieren und Krebszellen aus der Haut ziehen kann. Und die «Murmeltiersalbe» mit Murmelifett aus frischer Schweizer Jagd ist eigentlich ein eigenes «Zu guter Letzt» wert. Workshops zum Selbermachen von (Heil-)Salben erfreuen sich heute schon bei den Jüngsten grosser Beliebtheit, vom Kindergeburtstag bis zum Museum.

Neulich lief ich am Anschlagkasten einer Kirche vorbei und las von der dort angekündigten Krankensalbung. Ich gebe $\mathrm{zu}$, dass ich liturgisch nicht sehr bewandert bin. Gemäss Wikipedia ist die Krankensalbung (vulgo: letzte Ölung) ein Sakrament der Stärkung und Ermutigung ernsthaft oder lebensbedrohlich erkrankter Menschen, das unter anderem auf den Jakobusbrief des Neuen Testaments zurückgeht. Auch die Krankensalbung hat ihre sinnliche Komponente, wenn in der Regel Stirn und Handinnenflächen mit Krankenöl (geweihtem Olivenöl) gesalbt werden.

Jede Darreichungs- und Verabreichungsform von Medikamenten hat so ihren eigenen Charakter, ihre eigene Sinnlichkeit, ihre eigene Symbolik, ihren eigenen Wert: die invasive Injektion (englisch: shot), die praktische Pille, die spürbare Salbe.

Salben können Balsam für die Seele und den Körper sein - auch wenn man danach nicht auf dem Besen davonfliegt.

Eberhard Wolff * 